\title{
SINTERING MECHANISMS IN BASE METAL CONDUCTORS
}

\author{
J. DEGRAEUWE, $\dagger$ E. BRAUNS, R. VAN OVERSTRAETEN, J. ROOS, and R. GOVAERTS \\ Katholieke Universiteit Leuven, Departement Elektrotechniek, Afdeling E.S.A.T. \\ Kardinaal Mercierlaan 94, 3030 Heverlee, Belgium
}

(Received October 23, 1979)

\begin{abstract}
Thick film conductors based on $\mathrm{Al}, \mathrm{Cu}$ and $\mathrm{Ni}$ have been studied. Because of its high depth of field, a SEM was used to study the microstructures of the fired conductors.

Because of the very small size of the particles in commercial $\mathrm{Cu}$ pastes the neck growth forms part of the grain growth mechanism.

The bonding between the particles is much stronger in $\mathrm{Cu}$ than in $\mathrm{Al}$ films; this seems to be the reason why the sheet resistance of a $\mathrm{Cu}$ film virtually reaches the theoretical minimum.
\end{abstract}

\section{INTRODUCTION}

A film conductor produced by thick film technology is obtained by firing a paste that contains a metal powder. The process transforming the powder into a conductor is generally described as sintering.

Sintering can be defined as a process by which the surface free energy of a powder compact decreases; but this definition does not describe how the geometry of the compact changes, neither does it specify the mass transfer mechanism involved.

Several theories concerning the sintering mechanism have been developed in powder metallurgy and in ceramics technology. ${ }^{1,2}$ During sintering, the particles are bonded together and the pores shrink. A qualitative theory dealing with grain growth during densification has been developed by Greskovich and Lay. ${ }^{3}$

The aim of the present study is to find out if these theories can give a better understanding of the firing process of a thick film conductor. The structure of fired conductors was examined with a SEM. There is practically no bonding between the particles in an $\mathrm{Al}$ film; whereas in a $\mathrm{Cu}$ film, there is neck growth followed by grain growth. In a $\mathrm{Ni}$ film, the particles are bonded together but there is no grain growth. It has also been observed that $\mathrm{Ag}$ and PdAg films behave in the same way as $\mathrm{Cu}$ films.

The effects of temperature and time on the firing process were studied. Pastes with and without glass - the so called fritless pastes - were compared.

$\dagger$ J. Degraeuwe is supported by the I.W.O.N.L.

\section{REVIEW OF THEORIES RELATED TO THE SINTERING MECHANISM}

\subsection{Neck Growth and Pore Shrinkage}

When a powder compact is heated up to $70 \%$ to $90 \%$ of its melting temperature, sintering can occur. Sintering is usually divided into two overlapping stages. During the first, the particles are bonded together due to the necks growing between the particles. The density of the compact increases during the second stage because pores are eliminated.

The driving force in both stages is the excess surface free energy. Five mass transfer mechanisms can be responsible for the growth of necks and for the pore shrinkage: viscous flow, volume diffusion, surface- or grain-boundary diffusion and evaporation condensation. The sintering rate is determined by the mass transport mechanism.

It has been shown ${ }^{1,2}$ that in the idealized case of two sintering spheres (Figure 1) the equation relating the neck radius $(x)$, the particle radius $(a)$, time $(t)$

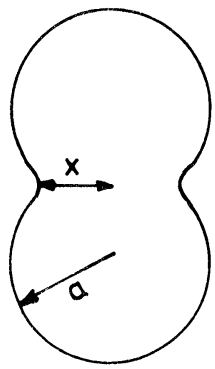

FIGURE 1 Basic model for sintering. 
and temperature $(T)$ is always of the form:

$$
\frac{x^{p}}{a^{q}}=K(T) t
$$

where $p, q$ and $K(T)$ depend on the mass transfer mechanism.

Table I gives the values of $p$ and $q$ for the different processes. Eq. (1) has several drawbacks for practical applications as it only holds for a very idealized geometry. Furthermore, different mechanisms may operate simultaneously.

Herring ${ }^{4}$ proposed a more precise method to determine the sintering mechanism. When two powders with geometrically similar particles (the linear dimensions of number two being $\lambda$ times those of number one) are sintered, they reach similar geometries $\left(x_{1} / a_{1}=x_{2} / a_{2}\right)$ after times $\Delta t_{1}$ and $\Delta t_{2}$ respectively; these time intervals are related as follows:

$$
\Delta t_{2}=\lambda^{n} \Delta t_{1}
$$

The values for $\mathrm{n}$ are also given in Table I.

It has been shown ${ }^{1,2}$ that the pores close because vacancies move by volume diffusion to the grain boundaries acting as vacancy sinks. Sintering in the presence of a liquid phase also leads to densification. The process consists of the solution and precipitation of the material in order to increase the density. ${ }^{5}$

TABLE I

Parameters of the neck growth mechanism

\begin{tabular}{llll}
\hline Mass transfer mechanism & $p$ & $q$ & $n$ \\
\hline Viscous flow & 2 & 1 & 1 \\
Evaporation condensation & 3 & 1 & 2 \\
Volume diffusion & 5 & 2 & 3 \\
Surface diffusion & 7 & 3 & 4 \\
Grain boundary diffusion & 6 & 2 & 4 \\
\hline
\end{tabular}

\subsection{Grain Growth}

Grain growth occurs in dense single-phase materials but also in very low-density powder compacts.

When a dense body is heated, grains smaller than a critical value will disappear in favour of the larger ones that will grow. ${ }^{6}$

In very porous powder compacts, grain growth occurs during the initial stage of the sintering, but the mechanism is quite different from that in a fully dense body. Greskovich and $\mathrm{Lay}^{3}$ proposed a four stage mechanism for grain growth in very porous $\mathrm{Al}_{2} \mathrm{O}_{3}$ compacts as shown in Figure 2. Coble, ${ }^{7}$

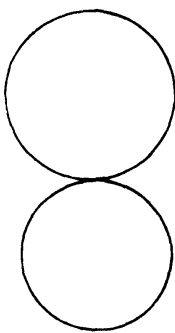

A
B

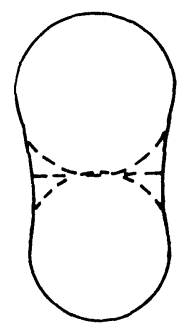

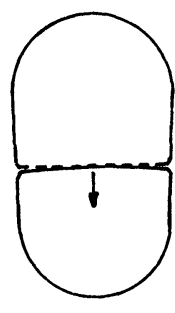

C

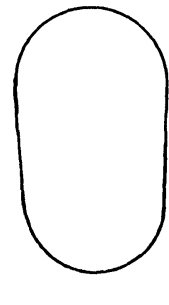

D
FIGURE 2 Four stages for grain in very porous compacts. ${ }^{3}$

A) Two particles come in contact with each other.

B) A neck grows between the two particles and a grain boundary appears at the contact interface.

C) The grain boundary migrates towards its centre of curvature.

D) An elongated particle has been formed.

Kuczynski ${ }^{8}$ and Ikegami et al..$^{9}$ have also developed theories dealing with densification with simultaneous grain growth, but they obtained different and irreducable relations.

\section{EXPERIMENTS ON THICK FILM CONDUCTORS}

This study was started to find out if the above mentioned theories can be applied to the sintering of a thick film conductor.

The following conclusions can be drawn:

\subsection{Aluminium}

$\mathrm{Al}$ pastes were fired in air at peak temperatures varying between $600^{\circ} \mathrm{C}$ and $700^{\circ} \mathrm{C}$. The SEM photographs of fired $\mathrm{Al}$ conductors show poorly bonded particles (Figure 3).

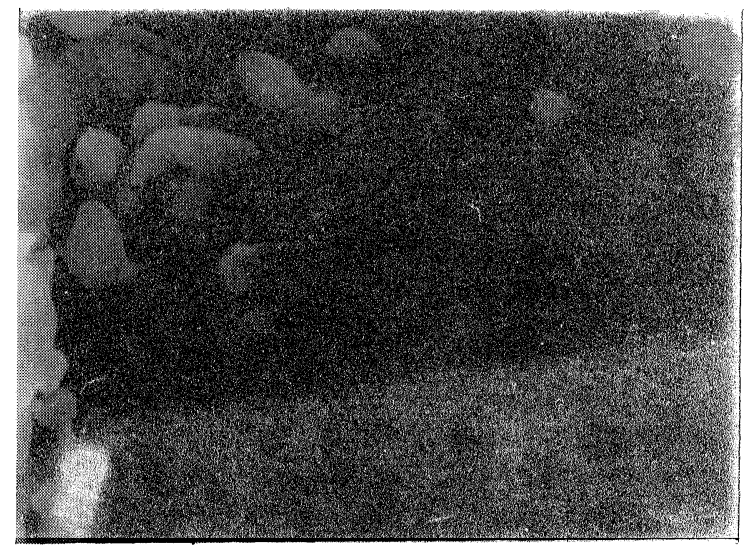

FIGURE $3 \mathrm{Al}$ film (Engelhard $\mathrm{T}-2497$ ) fired for $50 \mathrm{~min}$ at $600^{\circ} \mathrm{C}(1800 \mathrm{x})$. 
A comparison between $\mathrm{Al}$ pastes with and without glass (Engelhard T2497 and T2848) showed that the glass improved the adhesion to the substrate $(96 \%$ $\mathrm{Al}_{2} \mathrm{O}_{3}$ ). The two-sphere model cannot be applied to such a film, moreover Al pastes are optimally fired at or even above the melting temperature of $\mathrm{Al}$ $\left(660^{\circ} \mathrm{C}\right)$. So, it is obvious that there is no sintering in the sense dealt with above, but there is probably a sintering between the oxide-skins of the Al-particles. These oxide-skins hinder the diffusion of the $\mathrm{Al}$ atoms from one particle to another, excluding neck growth in this case.

\subsection{Copper}

A paste based on a spherical $\mathrm{Cu}$ powder with a maximum diameter of $45 \mu \mathrm{m}$ was prepared. When this paste was fired, the necks growing between the particles were clearly observed.

Herring's scale laws show that smaller particles sinter much quicker than larger ones. The particles used in commercial $\mathrm{Cu}$ pastes are much smaller than those that were used in our paste, so neck growth can proceed much faster in a commercial paste.

Figure 4a shows five firing profiles with the same peak temperature.

The firing time was varied by stopping the belt for a certain time at $T_{\text {peak }}$. Using this method, the substrates were always heated and cooled at the same rate.

When SEM photographs (Figure 5) of $\mathrm{Cu}$ films that have been fired according to the profiles of Figure 4a, are compared, considerable grain growth is observed. The sintering mechanism of these $\mathrm{Cu}$ films seems very similar to that of very porous $\mathrm{Al}_{2} \mathrm{O}_{3}$ compacts. Different $\mathrm{Cu}$ pastes (ESL 2310 and 2311, Dupont 9922, Plessey C-1500) have been fired according to the profiles of Figure 4a. The same evolution of the microstructures was observed.

In Figure $4 b$, the sheet resistances of $\mathrm{Cu}$ conductors with and without glass (ESL 2310 and 2311) are plotted as a function of $t_{0.9}$, i.e. the time that the profile was above $0.9 T_{\text {peak }}$. A retarding effect due to the presence of glass is observed.

When a $\mathrm{Cu}$ conductor is etched for a long time in a $5 \% \mathrm{HF}$ solution, the film can be removed as a foil. The same effect occurs with $\mathrm{Ag}$ and Ni films. In an $\mathrm{Al}$ conductor however, the film is decomposed into the original powder particles when it is etched. This happens probably because the $\mathrm{Al}_{2} \mathrm{O}_{3}$ bondings between the particles are dissolved by the HF. This shows the strong particle-particle bonding in $\mathrm{Cu}, \mathrm{Ag}$ and $\mathrm{Ni}$ conductors.

The sheet resistance of a fired $\mathrm{Cu}$ conductor is only twice its theoretical minimum value whereas the sheet resistances of fired $\mathrm{Al}$ and $\mathrm{Ni}$ conductors are ten times higher than their respective theoretical minimum values. This can be explained by the observed microstructures of the different conductors (Figures 3, 5, 6). It can also be remarked that the oxide-skins $\left(\mathrm{Al}_{2} \mathrm{O}_{3}\right.$ and $\left.\mathrm{NiO}\right)$ of the particles prevent a good bonding between the particles and hinder grain growth.

Table II gives a comparison between the specified sheet resistances and the theoretical minimum sheet resistances of some metals.

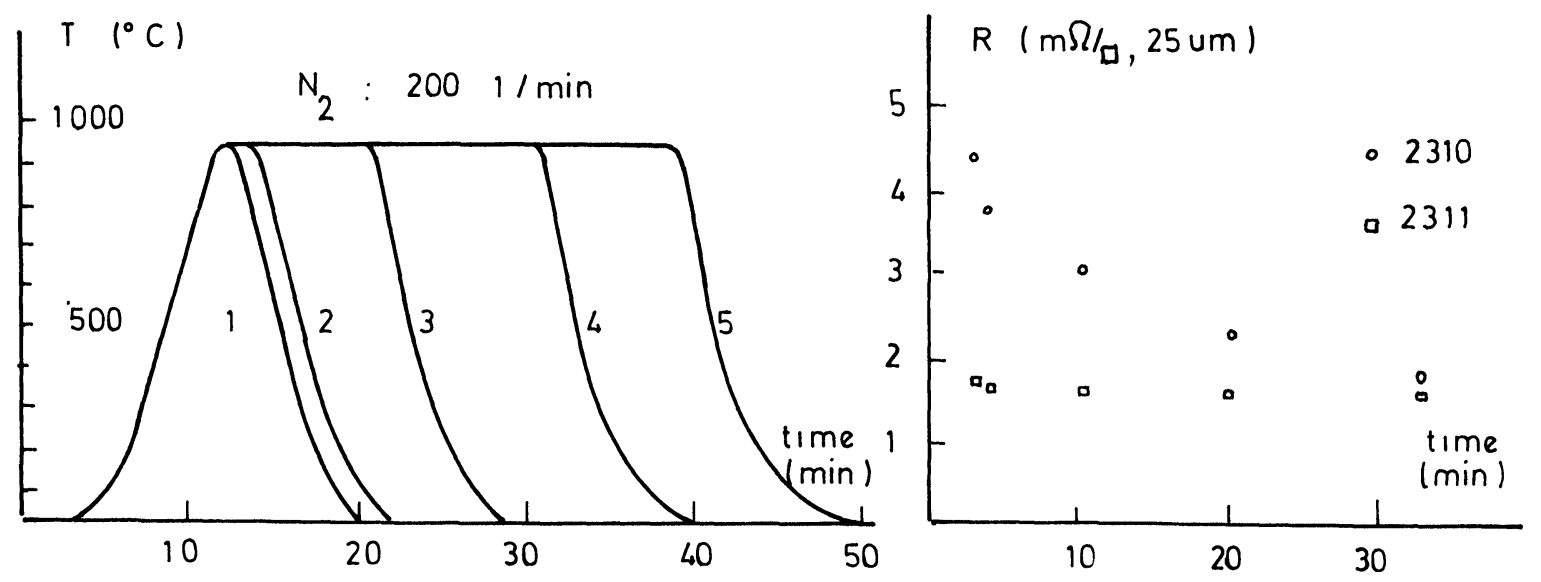

FIGURE 4 (a) Five firing profiles with the same peak temperature. (b) Sheet resistances of Cu conductors as a function of $t_{0.9}$. 

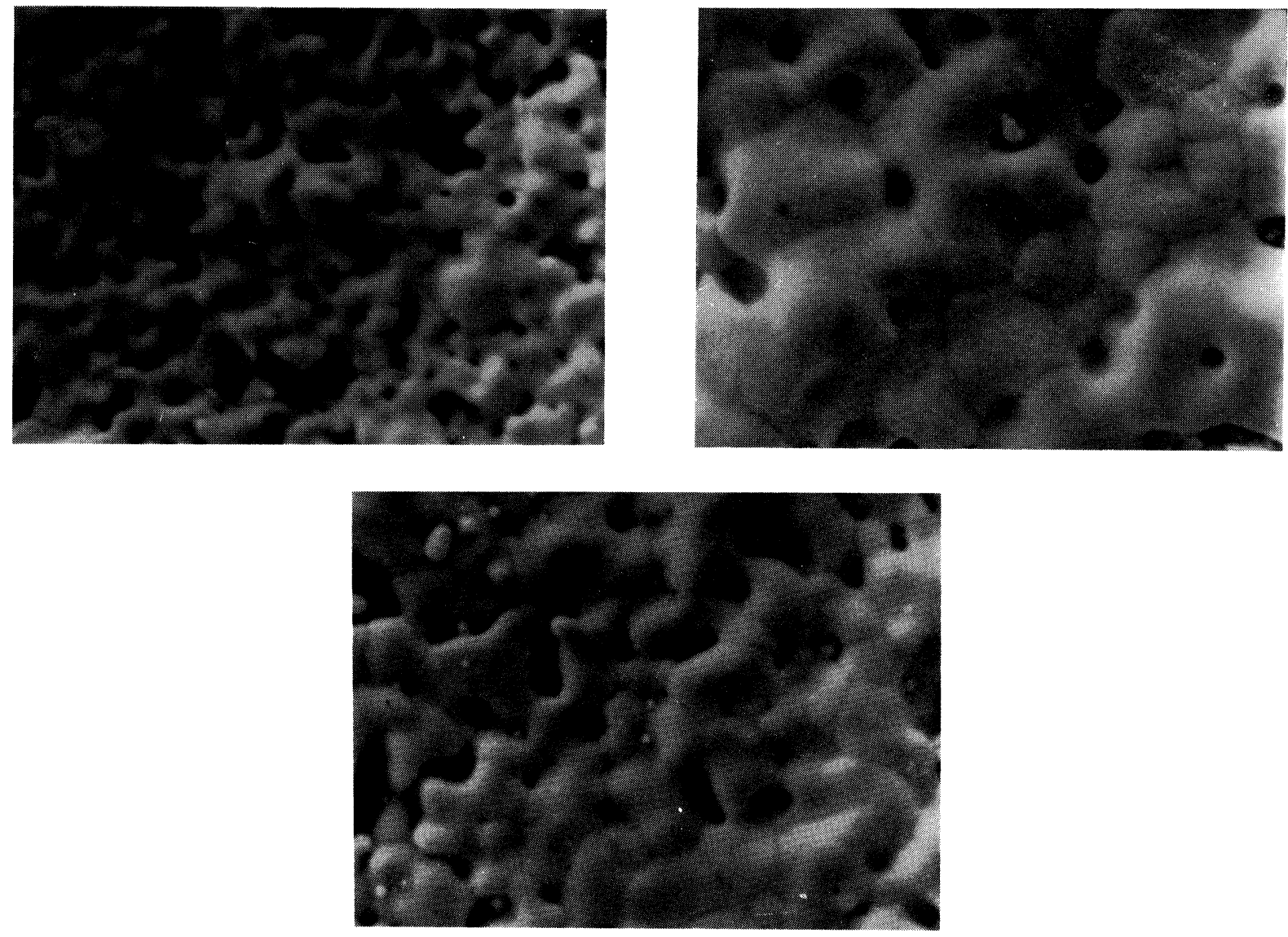

FIGURE 5 Cu films (ESL 2311) fired according to profiles 1, 3 and 5 of Figure $4 \mathrm{a}(1200 \mathrm{x})$.

TABLE II

Sheet resistances of some metals (mohm/ $\square, 25 \mu \mathrm{m})$

\begin{tabular}{llc}
\hline & Theoretical minimum & Specified value \\
\hline $\mathrm{Ag}$ & 0.64 & $1.3-5$ \\
$\mathrm{Al}$ & 1.04 & 14 \\
$\mathrm{Cu}$ & 0.67 & $1.0-2.5$ \\
$\mathrm{Ni}$ & 3.12 & $20-40$ \\
\hline
\end{tabular}

\subsection{Nickel}

In a $\mathrm{Ni}$ conductor, the particles are bonded together, but no grain growth is observed (Figure 6). The ESL Ni 2553 paste and the Plessey Ni paste $\mathrm{C}-1125$ must be fired in nitrogen, whereas the Engelhard Ni 2848 paste can be fired in air; this is made possible by additives that prohibit oxidation. Ni films in air have a higher sheet resistance, but this can be an advantage (e.g. electrodes for displays).

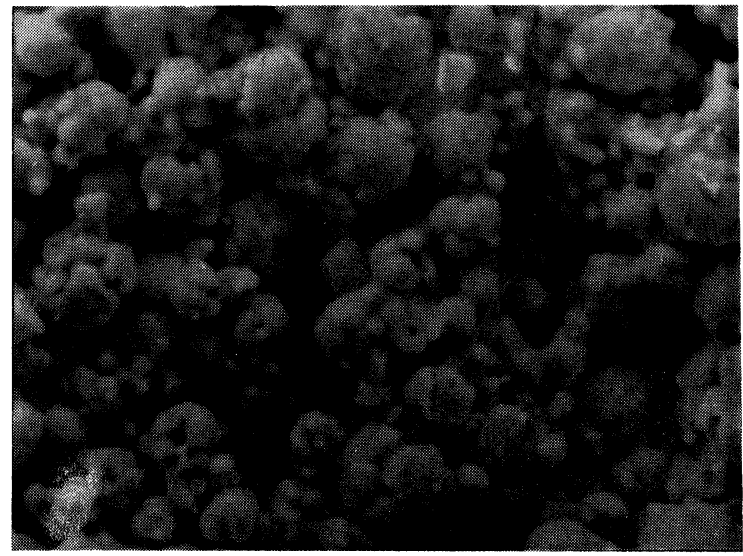

FIGURE 6 Ni film (ESL 2553) fired for $20 \mathrm{~min}$ at $850^{\circ} \mathrm{C}(1200 \mathrm{x})$. 

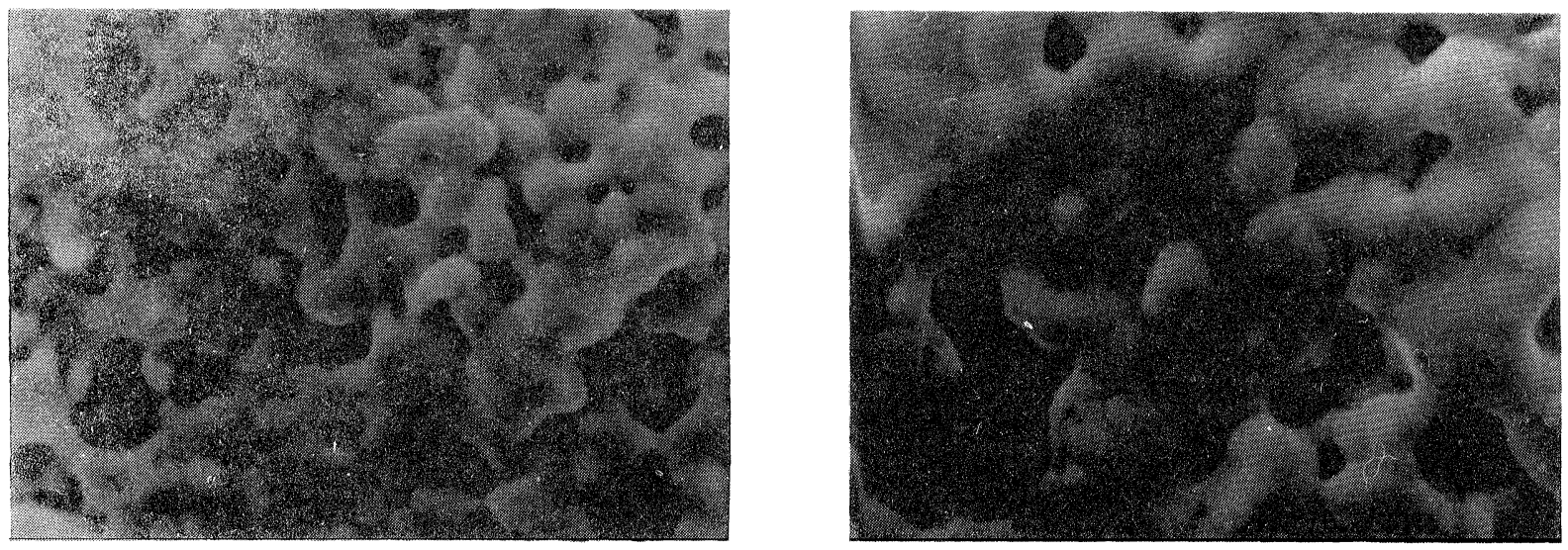

FIGURE 7 PdAg films (ESL $9635 \mathrm{~B}$ ) fired for 4 and $35 \mathrm{~min}$. at $810^{\circ} \mathrm{C}(3000 \mathrm{x})$.

\subsection{Comparison Between the Sintering Mechanisms of Copper and Silver}

Cole $^{10}$ determined the sintering mechanism in a PdAg film by measuring the shrinkage of cylinders made from the paste.

He concluded that in a fritless paste, the sintering occurred by grain boundary diffusion and that the sintering was enhanced by a solution precipitation mechanism in a paste that contained glass. The study of a PdAg paste (ESL 9635 B) by scanning electron microscope revealed however an obvious grain growth during sintering (Figure 7). This implies that solution-precipitation is not the only mechanism involved. Also in an Ag film (ESL 5965 and Plessey C--8600) grain growth during sintering was observed.

It can be concluded from these experiments that the two $\mathrm{Ib}$ metals $\mathrm{Ag}$ and $\mathrm{Cu}$ do behave in a very similar way when low-density compacts of their powders are fired.

\section{CONCLUSION}

It has been shown that the theories concerning neck growth, densification and grain growth as found in the literature, throw light upon the sintering of thick film conductors.

Because of its high depth of field, the SEM was very useful in examining the microstructures of the fired conductors.

Because of the very small size of the particles in commercial $\mathrm{Cu}$ and $\mathrm{Ag}$ pastes, the neck growth forms part of the grain growth mechanism.
The bonding between the particles is much stronger in $\mathrm{Cu}$ than in $\mathrm{Al}$ films, because the oxideskins hinder the bonding between the $\mathrm{Al}$ particles. This also seems to be the reason why the sheet resistance of $\mathrm{Ag}$ and $\mathrm{Cu}$ films virtually reaches the theoretical minimum.

\section{ACKNOWLEDGEMENTS}

The research activities presented in this contribution have been partly supported by the Science Policy Programs of the Belgian Government and the Institute for Scientific Research in Industry and Agriculture (IWONL).

\section{REFERENCES}

1. G. C. Kuczynski, Fundamentals of Sintering, in: Powder Metallurgy for high-performance applications, J. J. Burke \& V. Weis (ed.), Syracuse University Press, (1972), $101-117$.

2. W. D. Kingery, H. K. Bowden and D. R. Uhlman, Introduction to ceramics, Join Wiley \& Sons, (1976).

3. C. Greskovich and K. W. Lay, Grain growth in very porous $\mathrm{Al}_{2} \mathrm{O}_{3}$ compacts, J. Am. Cer. Soc. 55, (1972), $142-146$.

4. C. Herring, Effect of change of scale on sintering phenomena, J. Appl. Phys. 21, (1950), 301-303.

5. W. D. Kingery, Densification during sintering in the presence of a liquid phase. I. Theory, J. Appl. Phys. 30, (1959), 301-306.

6. K. W. Lay, Grain growth during sintering, Proc. Third Conf. on Sintering and Related Phenomena, Notre Dame (1972), 65-80.

7. R. L. Coble, Sintering crystalline solids: I. Intermediate and final state diffusion models, J. Appl. Phys. 32, (1961), 787; and Sintering Crystalline Solids: II. Experimental test of diffusion models in powder compacts, J. Appl. Phys. 32, (1961), 793. 
8. G. C. Kuczynski, Pore shrinkage and Ostwald ripening, Proc. Third Conf. on Sintering and Related Phenomena, Notre Dame, (1972), 217-224.

9. Ikegami et al., A model of densification with simultaneous grain growth, J. Appl. Phys. 49, (1978), 4238-4241.
10. S. S. Cole, Jr., The sintering mechanism in a silverpalladium film, Proc. Int'l Microelectronic Symp. (1972). 2.A.-1-1 - 2.A.-1-6. 

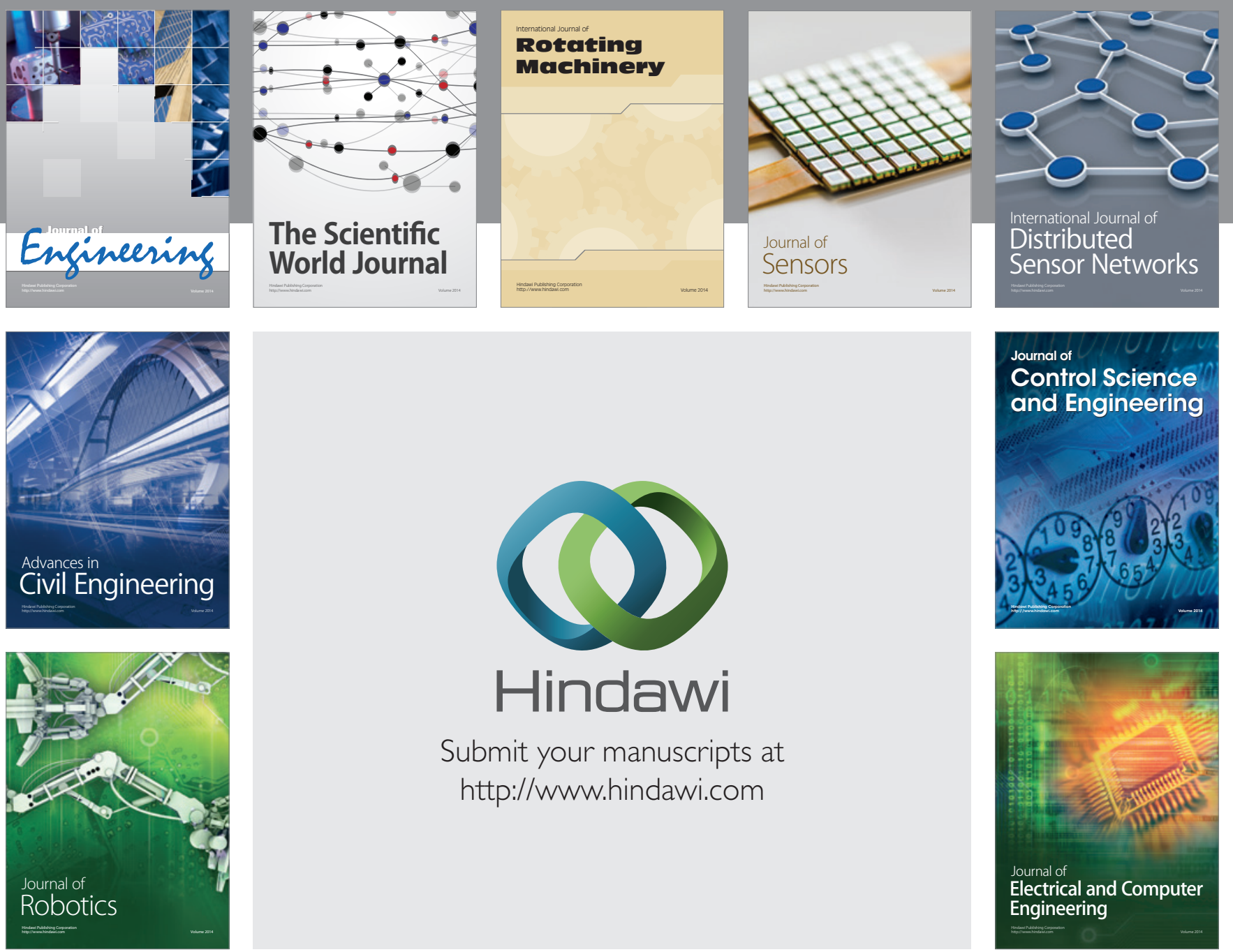

Submit your manuscripts at

http://www.hindawi.com
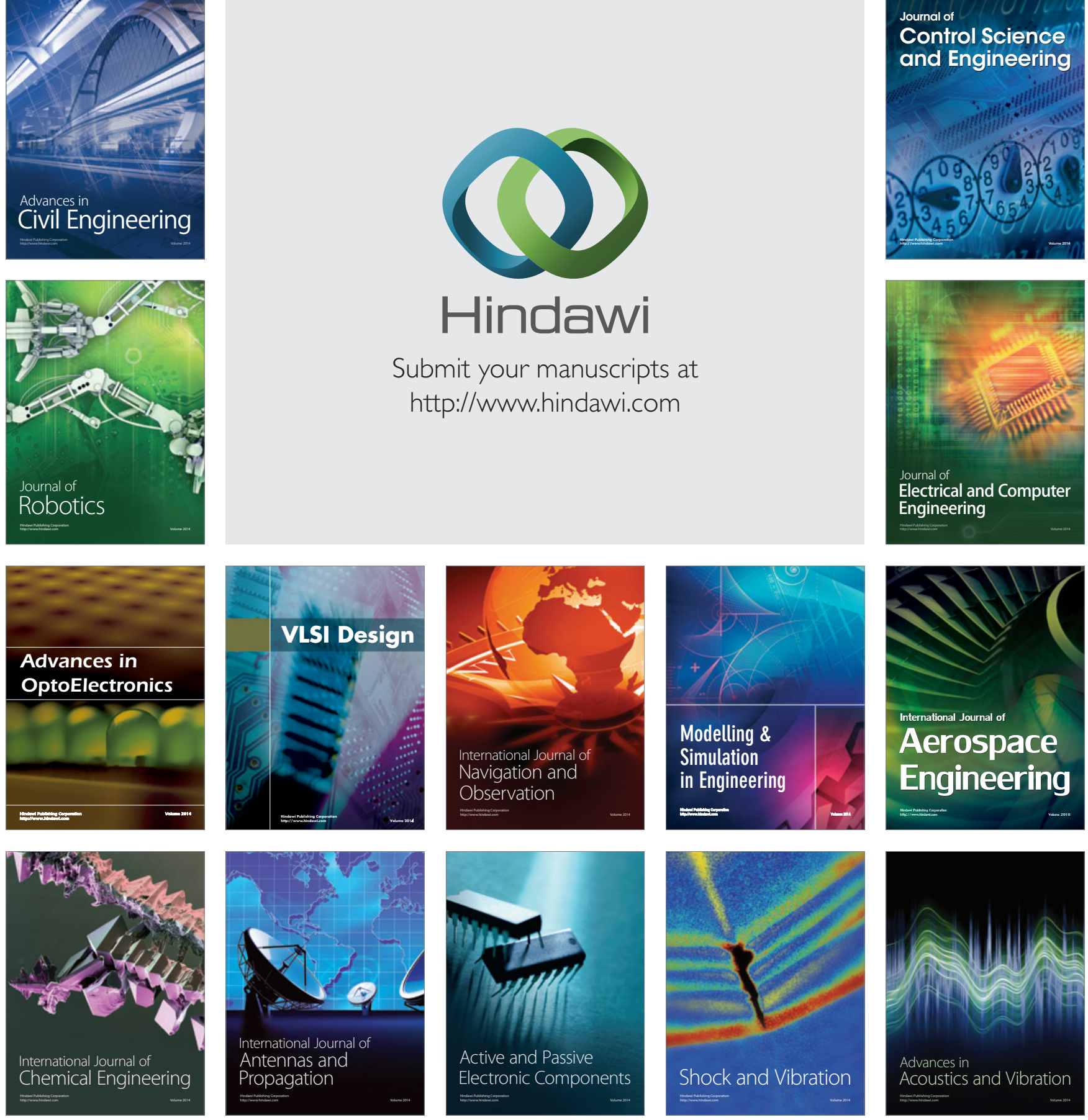